\title{
Elastic Critical Stress for Trapezoidal Sheeting with Flange and Web Stiffeners
}

\section{Torsten Höglund*}

Department of Civil and Architectural Engineering, Steel Structures, Royal Institute of Technology, Sweden

Submission: January 10, 2020; Published: February 03, 2020

${ }^{*}$ Corresponding author: Torsten Höglund, Department of Civil and Architectural Engineering, Royal Institute of Technology, KTH Stockholm, Sweden

Abstract

In Höglund, T. "Design of trapezoidal sheeting provided with stiffeners in the flanges and webs". Swedish Council for Building Research Document D28:1980 [1], the formulae for the design of trapezoidal sheeting with flange and web stiffeners are derived. In Eurocode 3, Part 1-3 only the simplified conservative formula is used as the background formulae are supposed to be too complicated in a code. However, they better agree with tests and are therefore given here.

Keywords: Trapezoidal sheeting; Stiffeners in flanges and webs; steel; Aluminium; Bending moment;

\section{Elastic Critical Stress}

In Eurocode 3, Part 1-3 [2] and Eurocode 9, Part 1-4 [3], the modified elastic critical stress for sheeting with flange stiffeners and web stiffeners is given by the formula

$$
\sigma_{\mathrm{cr}, \mathrm{mod}}=\frac{\sigma_{\mathrm{cr}, \mathrm{s}}}{\sqrt[4]{1+\left(\beta_{s} \frac{\sigma_{\mathrm{cr}, \mathrm{s}}}{\sigma_{\mathrm{cr}, \mathrm{sa}}}\right)^{4}}}(1)
$$

where $\sigma_{\mathrm{cr}, \mathrm{s}}$ and $\sigma_{\mathrm{cr}, \mathrm{sa}}$ are the elastic buckling stresses for a section with stiffeners in the flange only and stiffener in the webs only respectively.

As an alternative to the expression (1) the expressions in [1] gives better agreement with the tests

$$
\sigma_{\mathrm{cr}, \bmod }=\frac{N_{\mathrm{cr}}}{A_{\mathrm{s}}}
$$

where the elastic critical load for the stiffener in the flange is

$$
N_{\mathrm{cr}}=\min \left(k_{11}\right) \cdot E I_{\mathrm{s}}(3)
$$

and $k_{11}$ is found in 2 for one stiffener and 3 for two stiffeners in the compression flange.

\section{One Stiffener in the Compression Flange}

Calculate the buckling coefficient $k_{11}$ for different buckling length $l$ using

$$
\lambda=\delta / l
$$

where

$$
k_{11}=\frac{B_{\lambda}}{2 A_{\lambda}}-\sqrt{\left(\frac{B_{\lambda}}{2 A_{\lambda}}\right)^{2}-\frac{C_{\lambda}}{A_{\lambda}}}
$$

$$
\begin{gathered}
A_{\lambda}=\beta \lambda^{4}(6) \\
B_{\lambda}=(1+\beta) \lambda^{6}+\left(\alpha_{22}+\beta \alpha_{11}\right) \lambda^{2}(7) \\
C_{\lambda}=\lambda^{8}+\lambda^{4}\left(\alpha_{11}+\alpha_{22}\right)+\alpha_{11} \alpha_{22}-\alpha_{21} \alpha_{12}
\end{gathered}
$$

The formulae for $\alpha_{11}, \alpha_{12}, \alpha_{21}$ and $\alpha_{22}$ in (6), (7) and (8) are

$$
\begin{aligned}
& \alpha_{11}=\frac{1}{A_{n} \cdot E I_{\mathrm{s}}}\left[a_{1}^{2} s_{1}\left(1-\frac{a_{1}}{s_{1}}\right)^{2}-\frac{a_{1}^{2} s_{1}^{2}}{2\left(3 b_{1}+2 s_{1}\right)}\left(1-\frac{a_{1}^{2}}{s_{1}^{2}}\right)^{2}\right] \frac{1}{3 D}^{(9)} \\
& \alpha_{12}=\frac{1}{A_{n} \cdot E I_{\mathrm{s}}}\left[\frac{a_{1} s_{1} b_{1} b_{\mathrm{p}}}{3 b_{1}+2 s_{1}}\left(1-\frac{a_{1}^{2}}{s_{1}^{2}}\right)\left(1-\frac{b_{\mathrm{p}}^{2}}{b_{1}^{2}}\right)\right] \frac{1}{3 D}{ }^{(10)} \\
& \alpha_{21}=\frac{1}{2 \cdot A_{n} \cdot E I_{\mathrm{sa}}}\left[\frac{a_{1} s_{1} b_{1} b_{\mathrm{p}}}{3 b_{1}+2 s_{1}}\left(1-\frac{a_{1}^{2}}{s_{1}^{2}}\right)\left(1-\frac{b_{\mathrm{p}}^{2}}{b_{1}^{2}}\right)\right] \frac{1}{3 D}
\end{aligned}
$$

$$
\alpha_{22}=\frac{1}{A_{n} \cdot E I_{\mathrm{sa}}}\left[\left(1+\frac{3 s_{\mathrm{r}}}{b_{\mathrm{p}}}\right)-\frac{3 b_{1}}{3 b_{1}+2 s_{1}}\left(1+\frac{2 s_{\mathrm{r}}}{b_{\mathrm{p}}}\right)\left(1-\frac{b_{\mathrm{p}}^{2}}{b_{1}^{2}}\right)\right] \frac{b_{\mathrm{p}}^{3}}{6 D}(1
$$

$$
A_{n}=A_{11} A_{22}-A_{21} A_{12}
$$

$$
\beta=\frac{\beta_{\mathrm{s}} A_{\mathrm{sa}}}{I_{\mathrm{sa}}} \cdot \frac{I_{S}}{A_{\mathrm{s} . \mathrm{ef}}}(14)
$$


in which the notations for dimensions of flange and web parts are found in Figure 1 and $\beta_{\mathrm{S}}$ is according to [1] and the Eurocodes [2] and [3]

$$
\begin{aligned}
& \beta_{\mathrm{s}}=1-\left(h_{\mathrm{a}}+0,5 h_{\mathrm{ha}}\right) / e_{\mathrm{c}} \text { for the profile in bending; (15) } \\
& \beta_{\mathrm{S}}=1 \quad \text { for the profile in axial compression. }
\end{aligned}
$$

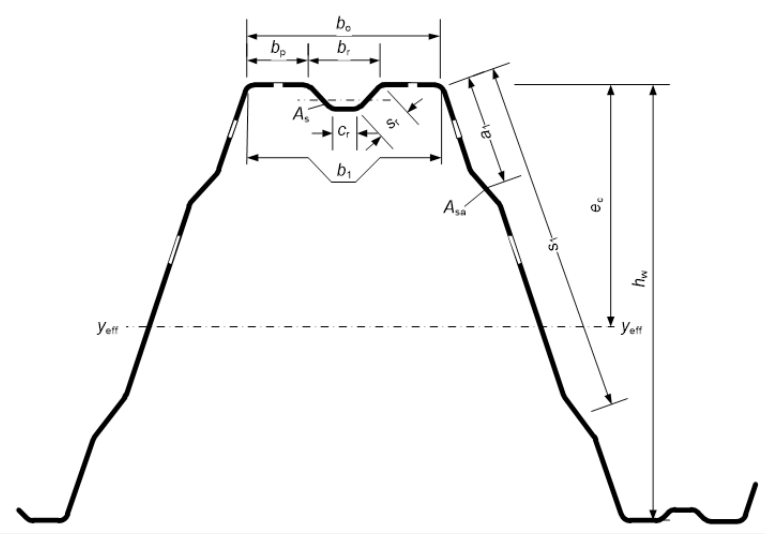

Figure 1:Trapezoidal sheeting with one flange stiffener and web stiffeners.

Further notations are

$D=\frac{E t^{3}}{12\left(1-v^{2}\right)}$ with $v=0,3$

flange stiffener

$A_{\mathrm{sa}}$ is the effective cross-section area of the intermediate web stiffener

$I_{s}$ is the second moment of inertia of the intermediate flange stiffener, see 5.5.3.4.3 in [2]

$\mathrm{I}_{\mathrm{sa}}$ is the second moment of inertia of the intermediate web stiffener, see 5.5.3.4.3 in [2]

The difference between the above formulae and the formulae in [1] is that the above formulae take the width of the stiffeners into account in transverse bending of the flange and webs.

\section{Two Stiffeners in the Compression Flange}

The formulae for $\alpha_{11}, \alpha_{12}, \alpha_{21}, \alpha_{22}$ and in expressions (F.9) to (F.12) are

$$
\begin{aligned}
& \alpha_{11}=\frac{1}{A_{n} \cdot E I_{\mathrm{s}}}\left[\left(3 \beta_{3}^{2}-4 \beta_{3}^{3}\right)-\frac{9 b_{1} \beta_{4}}{3 b_{1}+2 s_{1}}\right] \frac{b_{1}^{3}}{6 D} \\
& \alpha_{12}=\frac{1}{A_{n} \cdot E I_{\mathrm{s}}}\left[\frac{a_{1} s_{1} b_{1}^{2}}{3 b_{1}+2 s_{1}}\left(1-\frac{a_{1}^{2}}{s_{1}^{2}}\right)\left(\beta_{3}-\beta_{3}^{2}\right)\right] \frac{1}{2 D} \\
& \alpha_{21}=\frac{1}{A_{n} \cdot E I_{\mathrm{sa}}}\left[\frac{a_{1} s_{1} b_{1}^{2}}{3 b_{1}+2 s_{1}}\left(1-\frac{a_{1}^{2}}{s_{1}^{2}}\right)\left(\beta_{3}-\beta_{3}^{2}\right)\right] \frac{1}{2 D}
\end{aligned}
$$

$\alpha_{22}$ is the same as for one stiffener according to (12).

where the following notations are used

$$
\begin{gathered}
\beta_{3}=\left(b_{\mathrm{p}}+0,5 b_{\mathrm{r}}\right) / b_{1}(20) \\
\beta_{4}=\left(\beta_{3}-\beta_{3}^{2}\right)^{2}(21)
\end{gathered}
$$

The remaining expressions are the same as for one stiffener Figure 2.

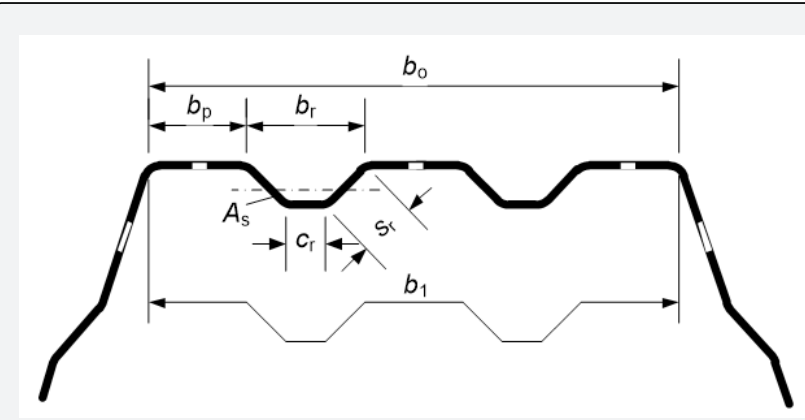

Figure 2: Flange with two stiffeners.

\section{Examples}

The trapezoidal sheeting with dimensions as in Figure 3 is calculated with the two methods which gives the result according to Table 1. In this example the web stiffeners are wide which means that the force in the stiffeners is large compared to the stiffness of the stiffener. Therefore, the increase of the resistance due to web stiffener is relatively small. For a cross section where the web stiffeners have smaller width-to-height ratio (Figure 4) the influence of the web stiffener is relatively larger.

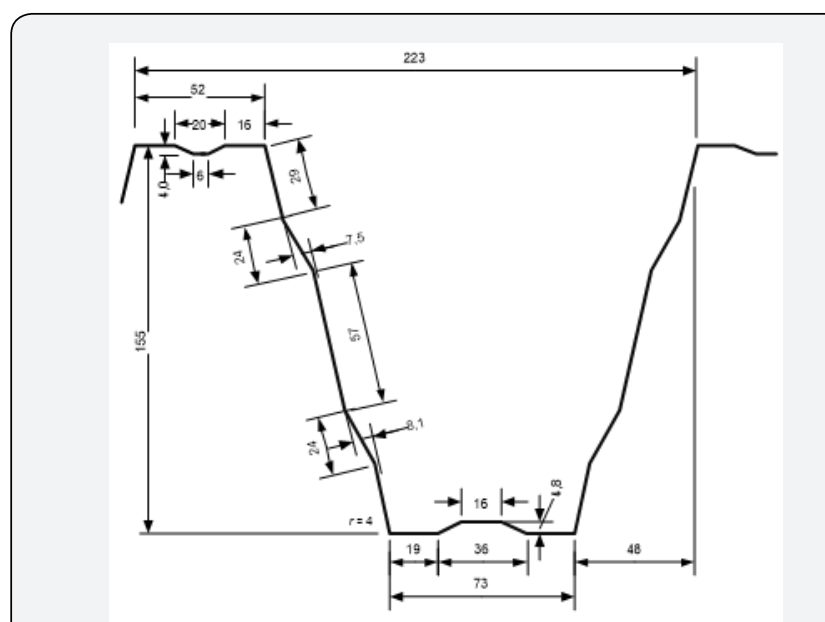

Figure3: Cross-section of trapezoidal sheeting $(\mathrm{mm})$ used in example. Steel thickness $0,56 \mathrm{~mm}$, yield stress $350 \mathrm{MPa}$.

\section{Conclusion}

The original formulae for the distortional buckling stress of the stiffeners of trapezoidal sheeting are improved so that the influence of transverse bending of the stiffeners are considered. 


\section{Civil Engineering Research Journal}

The buckling stress and the resistance is increased considerable if these formulae are used instead of the approximative formula in the Eurocodes for steel and aluminium.

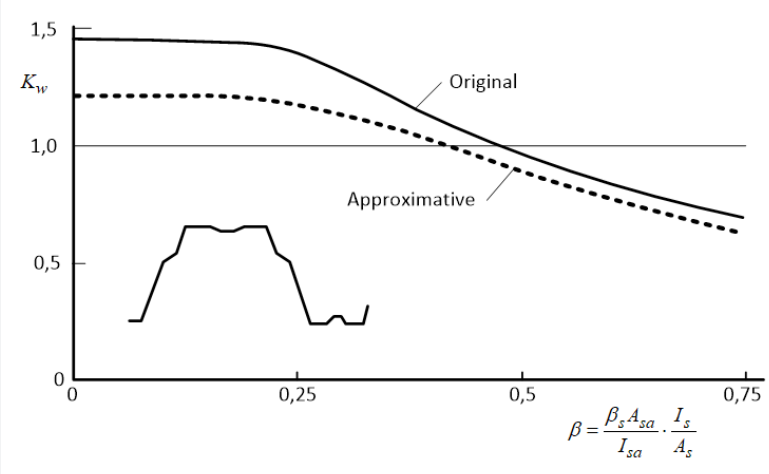

Figure 4:Comparison between original method and approximative formula for influence of web stiffener on the buckling load on the flange stiffener. $\beta$ is the relationship between the force in the web stiffener and force in the flange stiffener. After [1].
Table 1: Example of moment resistance according to approximative formula and original method.

\begin{tabular}{|c|c|}
\hline Method & $\begin{array}{c}\text { Moment Resistance } \\
/ \mathbf{k ~ N m} / \mathbf{m}\end{array}$ \\
\hline $\begin{array}{c}\text { Approximative formula (1), from the Euro- } \\
\text { codes [2] and [3] }\end{array}$ & 9,22 \\
\hline $\begin{array}{c}\text { Original method - formula (2) from [1] and } \\
\text { above formulae for } \alpha_{i j}\end{array}$ & 10,22 \\
\hline
\end{tabular}

\section{Acknowledgement}

Department of Civil and Architectural Engineering, Royal Institute of Technology, KTH Stockholm.

\section{References}

1. Höglund T (1980) Design of trapezoidal sheeting provided with stiffeners in the flanges and webs. Swedish Council for Building Research p. 82.

2. EN 1993-1-3 Eurocode 3: Design of steel structures - Part 1-3: General rules - Supplementary rules for cold-formed members and sheeting.

3. EN 1999-1-4 Eurocode 3: Design of aluminium - Part 1-4: Cold-formed structural sheeting.

\section{Your next submission with Juniper Publishers will reach you the below assets}

- Quality Editorial service

- Swift Peer Review

- Reprints availability

- E-prints Service

- Manuscript Podcast for convenient understanding

- Global attainment for your research

- Manuscript accessibility in different formats

( Pdf, E-pub, Full Text, Audio)

- Unceasing customer service

Track the below URL for one-step submission https://juniperpublishers.com/online-submission.php 